\title{
The favourable effect of Helicobacter pylori eradication therapy in patients with recurrent angina-like chest pain and non-responsive to proton pump inhibitors - a preliminary study
}

Jacek Budzyński ${ }^{1,2}$

1Department of Gastroenterology, Vascular Diseases and Internal Medicine, Nicolaus Copernicus University in Torun, Ludwik Rydygier Collegium Medicum, Bydgoszcz, Poland 2Division of Vascular Diseases and Internal Medicine, Dr Jan Biziel University Hospital No. 2, Bydgoszcz, Poland

Submitted: 17 July 2010

Accepted: 21 August 2010

Arch Med Sci 2011; 7, 1: 73-80

DOI: 10.5114/aoms.2011.20607

Copyright (c) 2011 Termedia \& Banach

\author{
Corresponding author: \\ Jacek Budzyński, MD \\ Division of Vascular Diseases \\ and Internal Medicine \\ Dr Jan Biziel University \\ Hospital No. 2 \\ Ujejskiego 75 \\ 85-168 Bydgoszcz, Poland \\ Phone/fax +48 523655347 \\ E-mail: budz@cps.pl
}

\begin{abstract}
Introduction: The outcome of Helicobacter pylori $(\mathrm{Hp})$ eradication therapy from the aspect of prevention of chest pain recurrence is still uncertain. The aim of this study was to assess the influence of Hp eradication therapy on the risk of hospitalization due to acute coronary syndrome.

Material and methods: The analysis was carried out in 63 consecutive patients with recurrent retrosternal symptoms: 28 (44\%) with significant coronary artery narrowing in coronarography not qualified for revascularization by an invasive cardiologist, and 35 (56\%) with no obstructive coronary artery lesions. In 33 (52\%) of the patients, $\mathrm{Hp}$ infection was found and standard eradication therapy with omeprazole $(2 \times 20 \mathrm{mg})$, amoxicillin $(2 \times 1 \mathrm{~g})$ and metronidazole $(2 \times 500 \mathrm{mg})$ was recommended. The mean follow-up period was $977 \pm 249$ days.

Results: Chest pain requiring hospitalization because of unstable angina within the follow-up period was observed in $9(27 \%)$ of the $\mathrm{Hp}$-infected individuals and in $15(50 \%)$ subjects in whom a urease test and histology did not confirm this infection $(p=0.055)$. The recommendation of Hp-eradication treatment was a significant factor prolonging the hospitalization-free period, both in the two Kaplan-Meier curve analyses (Cox's F test $=1.96 ; p=0.049$ ) and the Cox proportional hazard model (beta $=-1.18 ; p=0.045$ ), but was weaker than the effect of the non-obstructive coronary angiogram (beta $=-1.45 ; p=0.03$ ). Conclusions: The recommendation of $\mathrm{Hp}$-eradication therapy may prolong the hospitalization-free period for patients with recurrent chest pain.
\end{abstract}

Key words: Helicobacter pylori, eradication therapy, chest pain, angina pectoris.

\section{Introduction}

Helicobacter pylori ( $\mathrm{Hp}$ ) infection has been suspected of being a pathogenic factor in many diseases. However, its important pathophysiological role has been confirmed in only a few diseases of the upper digestive tract and recently also for haematological abnormalities (thrombocytopenic purpura and sideropenic anaemia) [1]. Helicobacter pylori is a frequent cause of gastric and duodenal ulcers and dyspepsia, as well as oesophageal motility disorders via its effects on the balance of the autonomic nervous system [2]. Helicobacter pylori infection has also 
been recognized as a factor both in diminishing and increasing the risk of gastro-oesophageal reflux disease (GERD), the most frequent cause of noncardiac chest pain (NCCP) $[3,4]$. The protective effect of this microorganism on the course of GERD has been explained by: (1) the induction atrophy of gastric corpus mucosa, secondary hypochlorhydria, and a reduction in oesophageal mucosa exposure to acid; (2) the greater antacid effect of the proton pump inhibitor (PPI) [5, 6]; and (3) a reduction in oesophageal inflammation by an increase in sympathetic tone and vagal activity $[2,4]$. The potential harmful influence of Hp infection on the course of GERD results from its stimulating effect on the cytokines and the synthesis of other inflammatory mediators. These seem to be more important in the pathogenesis of oesophagitis than oesophageal mucosa exposure to acid [7]. The above-mentioned role of $\mathrm{Hp}$ infection in GERD, oesophageal motility disorders, and gastric and duodenal ulcers pathogenesis may also potentially concern the recurrent chest pain originating from the digestive tract, which is a very important problem in health care [8-10].

However, Hp infection may play a potential role in the pathogenesis of chest pain, not only in individuals with normal coronary angiogram (NCCP) with cardiac syndrome $X$, but also in patients with coronary artery disease (CAD), both as a promotion effect of atherosclerotic plaque progression and instability, and as a result of the overlapping of the cardiac and upper digestive tract diseases observed in more than $30 \%$ of subjects [11-13]. The role of $\mathrm{Hp}$ infection in atherosclerosis complication evokes some doubts, but some epidemiological studies have shown that CagA seropositivity was significantly and positively associated with the occurrence of acute coronary events, atherosclerosis progression and arrhythmia prevalence [13-18]. The positive relationship of $\mathrm{Hp}$ infection with cardiac syndrome $X[19,20]$ has also been reported but not confirmed by others [21, 22], whereas Sandifer et al., based on the results of the EUROGAST Study Group, have shown a negative association between the seroprevalence of antibodies to $\mathrm{Hp}$ and the death rate from ischaemic heart disease [23].

A number of mechanisms for the influence of $\mathrm{Hp}$ on atherosclerosis complications have been suggested. It may act directly on atherosclerotic plaques, as suggested by the results of Kowalski et al., who revealed the presence of Hp DNA in atherosclerotic plaques and an increase in coronary artery diameter after microorganism eradication $[24,25]$. It was also implied that mimicry occurred between the cytotoxin-associated gene-A (CagA) antigen expressed by some $\mathrm{Hp}$ strains and the protein present in atherosclerotic plaques [13]. Helicobacter pylori infection, similarly to periodontal infection [26] or hepatitis C virus [27], may also act as one among a number of factors taking part in the mechanisms of pathogen burden through the following: non-specific inflammatory pathway stimulation (e.g. hsCRP increase); the induction of endothelial and microvascular dysfunction; an increase in adhesion molecule expression (e.g. VCAM-1, ICAM-1); the over-synthesis of cytokine (e.g. IL-1 $\beta$, IL-6, TNF- $\alpha$ ); changes in the autonomic nervous system balance $[2,28,29]$; and the production of metabolic changes, such as hypertriglyceridaemia, increased LDL cholesterol level, lipid oxidation, hyperfibrinogenaemia, altered blood coagulation and leukocytosis [20]. The role of $\mathrm{Hp}$ infection has also been reported as a cause of myocarditis and ECG changes in patients with persistent chest pain [30].

In considering that $\mathrm{Hp}$ infection may cause chest pain originating both from the heart and the oesophagus, both with and without obstructive lesions in a coronary angiogram, I have compared the 2.7-year follow-up course of recurrent chest pain in patients infected with $\mathrm{Hp}$ in whom eradication therapy was recommended, with subjects in whom this infection had not been diagnosed. To my knowledge, this is the first preliminary report to try to explain the role of $\mathrm{Hp}$ in patients with recurrent chest pain of suspected noncardiac origin and non-responsive to empirical therapy with a proton pump inhibitor (PPI).

\section{Material and methods}

This analysis was carried out in all of the 63 consecutive patients diagnosed in 2004-2006 because of recurrent angina-like chest pain defined as follows: precordial symptoms induced by exercise and receding after rest or taking nitroglycerine. All subjects were referred for gastroenterological diagnosis after cardiac work-up (history, physical examination, resting ECG, echocardiography, treadmill stress test, and coronary angiogram), and failed empirical therapy with PPIs. The origin of the chest pain being non-cardiac in character was suspected by the leading doctor, independently of the researcher, because of its recurrent course, resistance to treatment aimed at coronary reserve improvement, and the lack of signs of myocardial ischaemia in non-invasive examinations. Twenty-eight (44\%) patients had significant lesions, with $>50 \%$ of the coronary vessels narrowing but not being qualified for revascularization by the invasive-cardiologist (CAD group), and 35 (56\%) subjects revealed either a normal coronary angiogram or no obstructive lesions. All the subjects fulfilled the inclusion criteria: (1) aged between 40 and 70; (2) prior coronary angiography performance; (3) angina-like chest pain to the degree of class II or greater 
according to the Canadian Cardiovascular Society (CCS); and (4) persistent symptoms despite adequate anti-angina treatment and therapy for at least one month with a double dose of omeprazole $(2 \times 20 \mathrm{mg})$. The exclusion criteria were as follows: (1) changes in the ECG which make it impossible to estimate ischaemic signs (e.g. left bundle branch block or pre-excitation syndrome); and (2) the taking of medicines which may affect gastric acid secretion or digestive tract motility up to two weeks prior to the examination, with the exception of the ad hoc taking of nitroglycerine tablets. The demographic and clinical data of the subjects submitted for analysis are presented in Table I.

A panendoscopy was conducted using a videoendoscope from OLYMPUS. Biopsy specimens from the gastric corpus, angle and antrum were taken. $\mathrm{Hp}$ infection was diagnosed on the basis of histology and/or a urease test in 33 (52\%) patients. In all Hp-positive subjects, eradication therapy with omeprazole $(2 \times 20 \mathrm{mg})$, amoxicillin $(2 \times 1 \mathrm{~g})$ and metronidazole $(2 \times 500 \mathrm{mg})$ for 14 days was recommended. The $\mathrm{Hp}$ eradication rate was not checked, e.g. by using a breath test. After eradication therapy in all individuals, the continuation of a double dose of omeprazole (i.e. $2 \times 20 \mathrm{mg}$ ) was prescribed. In Hp-negative patients a double dose of omeprazole (i.e. $2 \times 20 \mathrm{mg}$ ) as monotherapy was recommended to start immediately after performance of the diagnostic procedure. Patients with CAD took their previously recommended standard therapy, i.e., at least acetylsalicylic acid, beta-blockers, angiotensinconverting enzyme inhibitors or statins.

Moreover, at the study beginning, in all patients, besides gastroenterological work-up, a treadmill stress test was performed. A clinically positive stress test was observed in 17 (51\%) Hp-positive subjects, and in 16 (53\%) Hp-negative subjects; 10 (30\%) Hppositive and 4 (13\%) Hp-negative individuals had an electrocardiographically positive stress test outcome (Table I). In none of the patients was simultaneous occurrence of angina-like chest pain and significant ( $\geq 1 \mathrm{~mm}$ ) ST interval depression observed.

For the entire observation period, patients were followed up in an outpatient clinic. However, in order to obtain reliable and objective data, information relating to the duration and causes of hospitalization in the database of social security numbers from the National Health Foundation (NHF) was received on 30 September 2007. The average observation period for the whole group of subjects was $977 \pm 249$ days. As, fortunately, the standard primary end points of death or myocardial infarction did not occur during the observation period, hospitalization due to acute coronary syndrome was established as the end point of the analysis. The decisions concerning subjects' hospitalization were taken independently of the researcher by the doctors working in the emergency rooms of the hospitals concerned. The main criteria for patients' admissions were as follows: an increase in chest pain frequency and strong, retrosternal chest pain resistant to nitroglycerine tablet application, which were not accompanied by ischaemic ECG changes. All hospitalized patients were diagnosed with unstable angina on discharge and such information was reported to the NHF (I.20.0 according to ICD-10 classification). The mean hospitalization-free period in the admitted individuals was $437 \pm 356$ days.

The study protocol was approved by the local Bioethics Committee of the Nicolaus Copernicus University in Torun and Collegium Medicum in Bydgoszcz, Poland. All subjects gave their informed consent prior to the start of the enrolment procedures. All procedures have been conducted in compliance with the Declaration of Helsinki.

\section{Statistical analysis}

Statistical analysis was conducted using a licensed version of the statistical software STATISTICA PL 8.0 for Windows. The results were presented as the mean \pm the standard deviation (SD) or $n(\%)$. The statistical significance of the differences between $\mathrm{Hp}$-infected and non-Hpinfected patients was verified using an unpaired Student's t-test or one-tailed Fisher exact test (Table I). Survival analysis was performed. The Wilcoxon-Gehan test and Cox's F test in the KaplanMeier method for two and many groups and Cox proportional hazard analysis were used.

\section{Results}

In 33 (52\%) subjects, Hp infection was diagnosed and eradication therapy recommended (Table I). Within the 2.7-year observation period, 24/63 (38\%) subjects were hospitalized due to suspected acute coronary syndrome, and discharged with the diagnosis of unstable angina (1.20.0 according to ICD-10 classification). None of them died, presented an increased level of cardiac troponin or needed a rescue coronarography. Among the hospitalized subjects, 14/24 (58\%) had obstructive changes in the coronary angiogram made before the observation period; $9 / 24$ (37\%) originated from the Hp-positive group, and 15/24 (63\%) came from the Hp-negative group ( $p=0.055)$. Therefore, patients from the Hp-negative group, for whom eradication therapy was not recommended, were borderline more frequently hospitalized due to acute coronary syndrome $(15 / 30 ; 50 \%)$ than patients earlier treated for $\mathrm{Hp}$ infection $(9 / 33 ; 27 \%)$, despite having presented a similar percentage of significant 
coronary artery narrowing and even borderline lower values of plasma lipids (Table I).

Moreover, this analysis has shown that the individuals who during gastroenterological workup were diagnosed as Hp-positive, in whom eradication therapy at the beginning of the study was recommended, had on average a longer period without hospitalization due to acute coronary syndrome than Hp-negative subjects (Table I). This favourable effect, which was connected with a recommendation of eradication treatment in $\mathrm{Hp}$ positive subjects, was confirmed by their survival, Kaplan-Meier analysis (Figure 1) and multi-factorial analysis using the Cox proportional hazard model (Table II). This analysis also showed that besides a recommendation of Hp-eradication therapy, other factors connected with a delayed risk of hospitalization due to acute coronary syndrome were as follows: normal coronary angiogram or no obstructive changes in the coronary arteries; a lower number of hospitalizations because of chest pain in the period prior to the eradication therapy recommendation; and female gender (Table II).
The investigated group consisted of patients both with and without significant coronary artery narrowing; thus the common effect of $\mathrm{Hp}$ eradication treatment and coronary angiogram on the risk of hospitalization due to acute coronary syndrome was additionally demonstrated (Figure 2). The defined model also achieved statistical significance $\left(\chi^{2}=9.7, p=0.021\right)$, and patients with an eradication therapy recommendation and without significant coronary artery narrowing ( $\mathrm{Hp}+$ (AD-) had a significantly lower risk of hospitalization than Hp-negative subjects with coronary artery disease (Hp-CAD+) $(p=0.048$, Cox's $F$ test) within the 2.7-year observation period.

\section{Discussion}

In this analysis the outcome of a Hp eradication therapy recommendation in patients with recurrent angina-like chest pain, both with and without CAD, was investigated. Its statistically significant favourable influence on the duration of hospitalization-free periods was confirmed both in basic statistics (Table I) and in advanced statistical

Table I. Demographic and clinical data for the patients studied

\begin{tabular}{|c|c|c|c|}
\hline Variable & $\mathrm{Hp}(+), n=33$ & $H p(-), n=30$ & $p$ \\
\hline Event-free period [days] & $884 \pm 316$ & $665 \pm 423$ & 0.02 \\
\hline Hospitalization because of acute coronary syndrome, $n(\%)$ & $9(27)$ & $15(50)$ & 0.055 \\
\hline Time to the first hospitalization [days] - in hospitalized subjects only & $573 \pm 397$ & $355 \pm 314$ & 0.15 \\
\hline Gender (male), $n$ (\%) & $12(36)$ & $20(67)$ & 0.02 \\
\hline Age [years] & $52.2 \pm 9.0$ & $56.6 \pm 7.3$ & 0.04 \\
\hline $\mathrm{BMI}\left[\mathrm{kg} / \mathrm{m}^{2}\right]$ & $27.9 \pm 3.9$ & $28.9 \pm 4.9$ & 0.46 \\
\hline WHR & $0.94 \pm 0.09$ & $0.9 \pm 0.08$ & 0.11 \\
\hline Smoking, $n(\%)$ & $5(15)$ & $1(3)$ & 0.19 \\
\hline Blood glucose $[\mathrm{mg} / \mathrm{dl}]$ & $100.0 \pm 17.6$ & $100.6 \pm 11.6$ & 0.93 \\
\hline Cholesterol [mg/dl] & $216.6 \pm 48.8$ & $192.6 \pm 39.0$ & 0.08 \\
\hline HDL cholesterol [mg/dl] & $49.5 \pm 8.2$ & $51.0 \pm 15.5$ & 0.70 \\
\hline LDL cholesterol [mg/dl] & $135.1 \pm 38.3$ & $114.6 \pm 15.5$ & 0.08 \\
\hline Triglycerides [mg/dl] & $162.4 \pm 78.2$ & $121.5 \pm 58.2$ & 0.07 \\
\hline History of myocardial infarction, $n(\%)$ & $3(9)$ & $8(27)$ & 0.16 \\
\hline History of hypertension, $n$ (\%) & $12(36)$ & $15(50)$ & 0.75 \\
\hline History of diabetes, $n(\%)$ & $4(12)$ & $6(20)$ & 0.72 \\
\hline History of $\mathrm{PCl}, n(\%)$ & $7(21)$ & $7(23)$ & 0.53 \\
\hline History of CABG, $n(\%)$ & $4(12)$ & $3(10)$ & 0.55 \\
\hline Esophagitis, $n(\%)$ & $4(12)$ & $4(13)$ & 0.90 \\
\hline$>50 \%$ narrowing of coronary, $n(\%)$ & $15(45)$ & $13(43)$ & 0.53 \\
\hline Angina-like chest pain during the stress test, $n(\%)$ & $10(30)$ & $4(13)$ & 0,16 \\
\hline Significant ST interval depression $\geq 1 \mathrm{~mm}, n(\%)$ & $17(51)$ & $16(53)$ & 0,080 \\
\hline
\end{tabular}

$B M I$ - body mass index, WHR - waist to hip ratio, $P C l$ - percutaneous coronary intervention, $C A B G$ - coronary artery bypass graft 
methods, as well as in survival analysis, in two(Figure 1), four- (Figure 2) and multi-factorial analyses (Table II). Factors other than Hp infection delaying the occurrence of the defined end point were as follows: normal coronary angiogram, female gender, and less frequent hospitalization before a gastroenterological chest pain work-up. Moreover, patients who were Hp-positive at the study beginning and were treated for $\mathrm{Hp}$ infection tended to be less frequently admitted due to acute coronary syndrome during the whole observation period.

The majority of reference data seems to confirm the results of my analysis, despite their being based on a mixed subject group consisting both of patients with normal coronary angiogram and those with significant narrowing of the coronary arteries. Some authors have reported a positive association between $\mathrm{Hp}$ infection, especially with CagA-positive strains and cardiac syndrome X $[19,20]$, and acute coronary syndromes $[13,14]$, although some have not confirmed this [21, 22, 31]. Moreover, the majority of physicians working in the Asia-Pacific region believe that Helicobacter pylori plays a role in NCCP pathogenesis [32]. The eradication of Hp, similarly to my study, was an effective treatment for patients with reflux-related NCCP after a 12month follow-up [33]. Nocente et al. reported a case of a 42-year-old man with cardiac syndrome $X$ in whom symptoms resolved after Hp eradication [34], and Kowalski et al. [24, 25] confirmed by angiography a decrease in coronary artery narrowing after a 6-month observation period following Hp-eradication therapy.

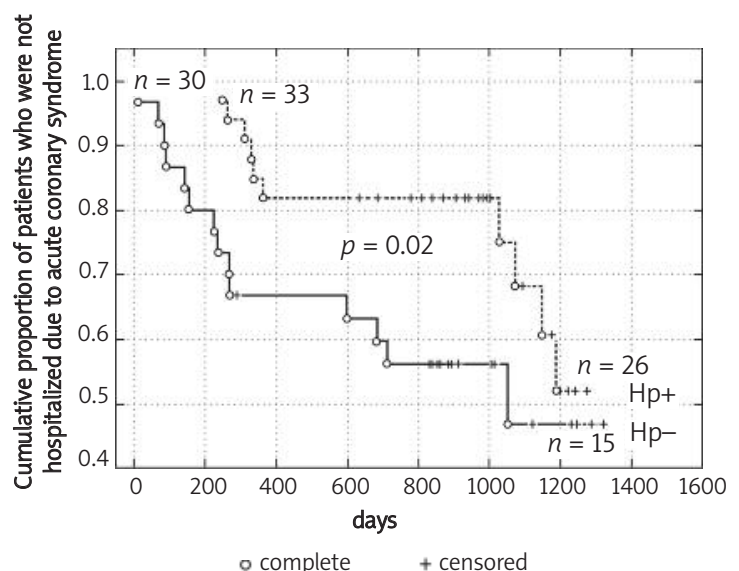

Figure 1. Comparison of two Kaplan-Meier curves as a function of time to the first hospitalization due to acute coronary syndrome in $\mathrm{Hp}$-infected patients and those without signs of infection (WilcoxonGehan test, $\mathrm{F}=2.33, p=0.020$; Cox's $\mathrm{F}$ test $=1.96$; $p=0.049$ ). The number of subjects in active followup in respective groups at the beginning and end of the study is presented as " $n=$ "

The advantage revealed in this study of eradication therapy with subsequent treatment with PPIs over therapy with PPIs alone in patients with recurrent chest pain might be explained in more than one way. Firstly, therapy with antibiotics might lead to a decrease in total pathogen burden [26], which might cause a reduction in the connected systemic inflammatory response and both an improvement in endothelial function [20] and a decrease in oesophagitis activity [7]. Secondly, the recommendation of Hp-eradication therapy

Table II. Cox Proportional Hazard Regression Model for the number of days to the first hospitalization due to suspected acute coronary syndrome $\left(\chi^{2}=30.40 ; p=0.008\right)$

\begin{tabular}{|lccc|}
\hline Independent variable & Beta & Standard error & $p$ \\
\hline Number of hospitalizations before gastrological diagnostic performance & -0.22 & 0.08 & 0.008 \\
\hline Hp-eradicative treatment recommendation & 1.18 & 0.59 & 0.045 \\
\hline Significant $>$ 50\% coronary vessel narrowing & -1.45 & 0.67 & 0.03 \\
\hline History of myocardial revascularization & -0.94 & 0.65 & 0.15 \\
\hline Gender (male/female) & -1.55 & 0.74 & 0.04 \\
\hline Canadian Cardiovascular Society classification (II or III) & 0.32 & 0.70 & 0.65 \\
\hline History of myocardial infarction & -0.25 & 0.80 & 0.76 \\
\hline Hypertension & 0.49 & 0.85 & 0.56 \\
\hline Diabetes mellitus & -0.05 & 0.73 \\
\hline Age & 0.06 & 0.04 \\
\hline BMI & 0.10 & 0.09 \\
\hline WHR & -8.89 & 5.56 & 0.26 \\
\hline LDL cholesterol & -0.01 & 0.01 \\
\hline
\end{tabular}

Hp - Helicobacter pylori, BMI - body mass index, WHR - waist to hip ratio 


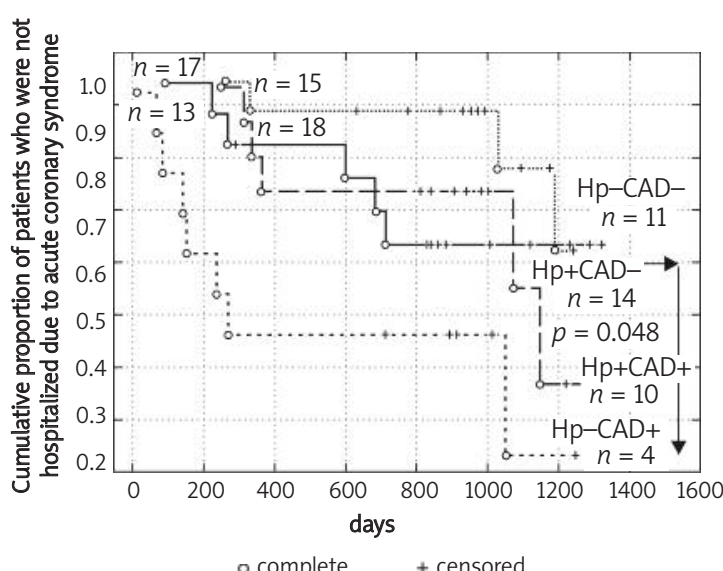

Figure 2. Comparison of four Kaplan-Meier curves as a function of time to the first hospitalization due to acute coronary syndrome in patients divided according to signs of $\mathrm{Hp}$ infection (positive $\mathrm{Hp}+$ or negative $\mathrm{Hp}$-) and significant coronary artery narrowing (CAD+ or CAD-) $\left(\chi^{2}=9.7 ; p=0.021\right)$. The number of subjects in active follow-up in respective groups at the beginning and end of the study is presented as " $\mathrm{n}=$ "

might have a psychological effect. The psychological aspect of chest pain recurrence has been underlined in a number of papers, concerning not only individuals with NCCP and a normal coronary angiogram, but also patients with $\operatorname{CAD}[8,9,35,36]$. Among the Polish population in general, $\mathrm{Hp}$ infection is recognized as a common cause of a number of symptoms, probably due to the high overall infection rate, which amounts to $73 \%$, and in subjects over 25 years of age to $85-95 \%$ [37]. In the studied population, Hp prevalence was lower (52\%). However, because $\mathrm{Hp}$ infection is associated with increased consultation due to GERD and/or dyspepsia [38], the potential elimination of the microorganism due to recommended eradication therapy might have a favourable effect. Thirdly, the potential elimination of $\mathrm{Hp}$ might have an effect on autonomic nervous system balance and might lead to an increase in the pain threshold, secondary changes in gastric acid secretion, oesophageal motility, and the degree of oesophagitis severity $[2,4,7,39]$.

My observations, like many others, have some limitations. Firstly, the study group was relatively small. However, on the PubMed database I could find only a few works concerning the gastroenterological aspects of chest pain with a number of subjects greater than in my study. The number of subjects in my study was sufficient to show a significant effect of eradication treatment in a comparison of the two groups (Figure 1), although not adequate to demonstrate this effect in a comparison of four groups (Figure 2). Regardless, I hope that my results present a sufficient premise for planning further study. Secondly, my subjects were not randomized for eradication therapy, which could lead to some selection bias and some baseline differences between the Hp-positive and Hp-negative group (Table I), which might influence the difference in outcome. However, the analysis included consecutive non-selected patients referred to the clinic by leading doctors, independent of the researcher, who suspected a noncardiac origin of symptoms in their patients independently of coronary artery status. Moreover, in both $\mathrm{Hp}$-infected and non-Hp-infected groups, the presence of infection was checked using the same diagnostic methods. Thirdly, the study design was not double-blind and placebo-controlled, but was primarily planned as an observational, not interventional, investigation. Moreover, the randomization of $\mathrm{Hp}$-infected, symptomatic patients to eradication therapy might evoke ethical doubts. Fourthly, the established end point of this study may be recognized as highly subjective and difficult to determine precisely. However, because the classical primary end point did not, fortunately, occur in any of the patients, choosing other, more usual, end points was not possible. Moreover, any decisions concerning patient hospitalization and establishment of the discharge diagnosis did not depend on the investigator but on the independent physicians working in the admission rooms and cardiology units of the hospitals concerned. On the one hand, this might be a source of bias, but on the other provides apparent random selection. In my opinion, the potential bias of my investigation was also reduced by the estimation of the eradication treatment effect just after obtaining data from the NHF. Fifthly, the investigated population was heterogeneous and consisted of patients both with and without significant coronary artery narrowing, and patients infected by Hp were younger and less frequently were of the male gender (Table I). However, the primary aim of this analysis was to compare the outcome of diagnostic and therapeutic procedures in patients with recurrent chest pain, suspected of being noncardiac in origin and non-responsive to double doses (i.e. $2 \times 20 \mathrm{mg}$ ) of omeprazole. Moreover, this limitation was diminished by the use of multi-factorial statistical analysis. The precise selection of patients into a homogeneous group could be planned for further study. Sixthly, the efficacy of Hp-eradication therapy was not checked, so it is not known if treating patients resulted in $\mathrm{Hp}$ being eradicated and if the revealed observations were an effect of the therapy alone or of microorganism eradication. However, the studied patients have no clinical indications regarding such procedures according to Polish recommendations [1]; the outcome of eradication therapy was not a primary end point of the analysis; and its 
favourable effect was found by chance, simply during analysis after receiving data from the NHF.

In conclusion, in this preliminary study $\mathrm{Hp}$ eradication therapy was one among a number of independent factors prolonging the time to the first hospitalization due to acute coronary syndrome in patients with recurrent angina-like chest pain nonresponsive to treatment with PPIs. A further, randomized and placebo-controlled investigation in a greater number of patients is needed regarding this observation.

\section{Acknowledgments}

The study was performed through a grant from the Nicolaus Copernicus University in Toruń, Ludwik Rydygier Collegium Medicum in Bydgoszcz for the statutory activity of the Department of Gastroenterology, Vascular Diseases and Internal Medicine.

These data have been presented at a meeting: the $16^{\text {th }}$ United European Gastroenterology Week, "UEGW 2008", Vienna, Austria, 18-22 October 2008 [Budzyński J. Helicobacter pylori eradication is independent and the most favorable therapeutic method in patients with recurrent noncardiac chest pain. Gut 2008; 57 (Suppl. II): A328 (P117)].

\section{References}

1. Dzieniszewski J, Jarosz M, Grupa Robocza PTG-E do spraw zakażenia Helicobacter pylori. Ustalenia Grupy Roboczej PTG-E dotyczące postępowania w zakażeniu Helicobacter pylori - consensus 2008 [Polish]. Gastroenterol Pol 2008; 15: 323-31.

2. Budzyński J, Kłopocka M, Bujak R, Świątkowski M, Pulkowski G, Sinkiewicz W. Autonomic nervous function in Helicobacter pylori-infected patients with atypical chest pain studied by analysis of heart rate variability. Eur J Gastroenterol Hepatol 2004; 16: 451-7.

3. Souza RC, Lima JH. Helicobacter pylori and gastroesophageal reflux disease: a review of this intriguing relationship. Dis Esophagus 2009; 22: 256-63.

4. Shahabi S, Rasmi Y, Jazani NH, Hassan ZM. Protective effects of Helicobacter pylori against gastroesophageal reflux disease may be due to a neuroimmunological antiinflammatory mechanism. Immunol Cell Biol 2008; 86: 175-8.

5. Kłopocka M, Budzyński J, Świątkowski M, Korenkiewicz L, Pulkowski G, Grad K. Influence of Helicobacter pylori infection on the results of 24-hour gastric $\mathrm{pH}$-metry in patients diagnosed because of atypical chest pain. Przegl Lek 2005; 62: 843-7.

6. Budzyński J, Kłopocka M, Świątkowski M, Korenkiewicz Ł, Pulkowski G, Grad K. Effect of Helicobacter pylori infection on the gastroesophageal reflux in patients with atypical chest pain. Pol Arch Med Wewn 2004; 111: 143-51.

7. Souza RF, Huo X, Mittal V, et al. Gastroesophageal reflux might cause esophagitis through a cytokine-mediated mechanism rather than caustic acid injury. Gastroenterology 2009; 137: 1776-84.

8. Dickman R, Fass R. Noncardiac chest pain. Clin Gastroenterol Hepatol 2006; 4: 558-63.
9. Fass R, Dickman R. Non-cardiac chest pain: an update. Neurogastroenterol Motil 2006; 18: 408-17.

10. Dickman R, Mattek N, Holub J, Peters D, Fass R. Prevalence of upper gastrointestinal tract findings in patients with noncardiac chest pain versus those with gastroesophageal reflux disease (GERD)-related symptoms: results from a national endoscopic database. Am J Gastroenterol 2007; 102: 1173-9.

11. Dobrzycki S, Baniukiewicz A, Korecki J, et al. Does gastroesophageal reflux provoke the myocardial ischemia in patients with CAD? Int J Cardiol 2005; 104: 67-72.

12. Budzyński J, Kłopocka M, Pulkowski G, et al. The effect of double dose of omeprazole on the course of angina pectoris and treadmill stress test in patients with coronary artery disease - a randomised, double-blind, placebo controlled, crossover trial. Int J Cardiol 2008; 127: 233-9.

13. Franceschi F, Niccoli G, Ferrante G, et al. CagA antigen of Helicobacter pylori and coronary instability: insight from a clinico-pathological study and a meta-analysis of 4241 cases. Atherosclerosis 2009; 202: 535-42.

14. Miyazaki M, Babazono A, Kadowaki K, Kato M, Takata T, Une $\mathrm{H}$. Is Helicobacter pylori infection a risk factor for acute coronary syndromes? I Infect 2006; 52: 86-91.

15. Pellicano R, Mazzarello MG, Morelloni S, et al. Helicobacter pylori seropositivity in patients with unstable angina. J Cardiovasc Surg (Torino) 2003; 44: 605-9.

16. Engelmann MD, Svendsen JH. Inflammation in the genesis and perpetuation of atrial fibrillation. Eur Heart J 2005; 26: 2083-92.

17. Montenero AS, Mollichelli N, Zumbo F. Helicobacter pylori and atrial fibrillation: a possible pathogenic link. Heart 2005; 91: 960-1.

18. Bunch TJ, Day JD, Anderson JL. Frequency of Helicobacter pylori seropositivity and $\mathrm{C}$-reactive protein increase in atrial fibrillation in patients undergoing coronary angiography. Am J Cardiol 2008; 101: 848-51.

19. Celik T, Iyisoy A, Yuksel UC. Possible pathogenetic role of Helicobacter pylori infection in cardiac syndrome X. Int J Cardiol 2010; 142: 193-4.

20. Eskandarian R, Malek M, Mousavi SH, Babaei M. Association of Helicobacter pylori infection with cardiac syndrome X. Singapore Med J 2006; 47: 704-6.

21. Ozdogru I, Kalay N, Dogan A, et al. The relationship between Helicobacter pylori IgG titre and coronary atherosclerosis. Acta Cardiol 2007; 62: 501-5.

22. Saleh N, Svane B, Jensen J, Hansson LO, Nordin M, Tornvall P. Stent implantation, but not pathogen burden, is associated with plasma C-reactive protein and interleukin-6 levels after percutaneous coronary intervention in patients with stable angina pectoris. Am Heart J 2005; 149: 876-82.

23. Sandifer QD, Vuilo S, Crompton G. Association of Helicobacter pylori infection with coronary heart disease. Association may not be causal. BMJ 1996; 312: 251.

24. Kowalski M, Konturek PC, Pieniazek P, et al. Prevalence of Helicobacter pylori infection in coronary artery disease and effect of its eradication on coronary lumen reduction after percutaneous coronary angioplasty. Dig Liver Dis 2001; 33: 222-9.

25. Kowalski M, Pawlik M, Konturek JW, Konturek SJ. Helicobacter pylori infection in coronary artery disease. J Physiol Pharmacol 2006; 57 (Suppl. 3): 101-11.

26. Shanker J, Kakkar VV. Role of periodontal infection in cardiovascular disease: a current perspective. Arch Med Sci 2009; 5: 125-34.

27. Ramdeen N, Aronow WS, Chugh S, Asija A. Patients undergoing coronary angiography because of chest pain 
with hepatitis C virus seropositivity have a higher prevalence of obstructive coronary artery disease than a control group. Arch Med Sci 2008; 4: 452-4.

28. Katoh K, Nomura M, Nakaya Y, et al. Autonomic nervous activity before and after eradication of Helicobacter pylori in patients with chronic duodenal ulcer. Aliment Pharmacol Ther 2002; 16 (Suppl. 2): 180-6.

29. Rasmi Y, Raeisi S. Possible role of Helicobacter pylori infection via microvascular dysfunction in cardiac syndrome X. Cardiol J 2009; 16: 585-7.

30. Navarese EP, Franceschi F, Aurelio A, Natale L, Rebuzzi AG, Gasbarrini G. Focal myocarditis mimicking ST-elevation myocardial infarction in a patient with Helicobacter pylori infection: role of magnetic resonance with late gadolinium enhancement. Recenti Prog Med 2010; 101: 61-3.

31. Delaney BC, Hobbs FD, Holder R. Association of Helicobacter pylori infection with coronary heart disease. Eradication of the infection on grounds of cardiovascular risk is not supported by current evidence. BMJ 1996; 312: 251-2.

32. Cheung TK, Lim PW, Wong BC. Noncardiac chest pain an Asia-Pacific survey on the views of primary care physicians. Dig Dis Sci 2007; 52: 3043-8.

33. Mesihović R, Vucelić B, Bratović I, Gribajcević M Selak I. Effect of eradication of Helicobacter pylori infection on endoscopic findings and symptoms of gastroesophageal reflux. Med Arh 2002; 56: 201-6.

34. Nocente R, Gentiloni N, Cremonini F, et al. Resolution of syndrome $\mathrm{X}$ after eradication of virulent CagA-positive Helicobacter pylori. South Med J 2000; 93: 1022-3.

35. Zaman MJ, Crook AM, Junghans C, et al. Ethnic differences in long-term improvement of angina following revascularization or medical management: a comparison between south Asians and white Europeans. J Public Health (Oxf) 2009; 31: 168-74.

36. Spencer HL, Smith L, Riley SA. A questionnaire study to assess long-term outcome in patients with abnormal esophageal manometry. Dysphagia 2006; 21: 149-55.

37. Jarosz M, Rychlik E, Siuba M, et al. Dietary and socioeconomic factors in relation to Helicobacter pylori reinfection. World J Gastroenterol 2009; 15: 1119-25.

38. Hungin AP, Hill C, Raghunath A. Systematic review: frequency and reasons for consultation for gastrooesophageal reflux disease and dyspepsia. Aliment Pharmacol Ther 2009; 30: 331-42.

39. Sarkar S, Thompson DG, Woolf CJ, Hobson AR, Millane T, Aziz Q. Patients with chest pain and occult gastroesophageal reflux demonstrate visceral pain hypersensitivity which may be partially responsive to acid suppression. Am J Gastroenterol 2004; 99: 1998-2006. 